
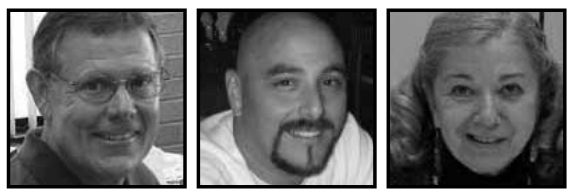

\title{
Theorizing an Integration of Reading and Mathematics: Solving Mathematical Word Problems in the Elementary Grades
}

\author{
William H. Rupley, Robert M. Capraro, \& Mary Margaret Capraro, \\ Texas A\&M University
}

\section{ABSTRACT}

This article theorizes three major cognitive constructs that are operationally defined by shared similarities of processing information in reading and mathematics. Specifically, the paper (1) proposes and details the refinement and evaluation of components of a conceptual model for reading to solve mathematical word problems for elementary students, and (2) develops and refines the theoretical constructs of the model. Our assumptions lay out the interrelationships of reading and mathematics word problems by focusing on the cognitive components of Recognizing Higher Level Patterns of Text Organization (R), Generating Patterns (G), and Attaining a Goal (A). These assumptions are to refine and construct the RGA cognitive components that could theoretically enhance elementary students' reading and solution of mathematical word problem-solving abilities.

WASHINGTON (Oct. 14, 2009) - There has been no significant change in the performance of the nation's 4th-graders in mathematics from 2007 to 2009, a contrast to the progress seen from 1990 to 2007 at that grade level and subject, according to the 2009 National Assessment Governing Board (2009) in mathematics.

istorically, several educational interventions have been suggested to improve mathematics achievement in the United States without a significant degree of robust success. Among the first that received broad 
attention, was the move to conceptual development using manipulatives in the New Math era (Driscoll, 1983; Fennema, 1972; Sowell, 1989; Suydam, 1986; Suydam \& Higgins, 1976). However, this innovation was questioned when in international student comparisons the U.S. performance did not improve (Baroody, 1989; cf. Clements \& McMillen, 1996). A gradual movement emerged in the field that resulted in a greater emphasis being placed on testing mathematics through contextualized problems referred to as word problems. The shift in emphases to word problems resulted in key word strategies gaining favor (Fuson, Carroll, \& Landis, 1996; Harris \& Pressley, 1991; Pressley, Levin, \& Delaney 1982); however the efficacy of this strategy failed to provide any dramatic change in student performance or improvement in the United States' international mathematics ranking (Mullis, Martin, \& Foy, 2008; Organisation for Economic Co-operation and Development [OECD], 2006).

Recently, Slavin and Lake (2008) comprehensively examined various types of current mathematics programs available by placing them on a common scale using best-evidence synthesis. They computed effect sizes and also provided a description of the context, design, and findings of each experimental study. The evidence from their review of 86 studies supported several conclusions: (1) there were few high quality studies, (2) more randomized program evaluations used over longer time periods were needed, (3) textbooks and mathematics curricula used for instruction did not matter much and little evidence of strong effects were found, and (4) studies of Computer Assisted Instruction contained modest effect sizes and some showed positive effects for computation. The most promising conclusion to assist with theoretical reformation from Slavin and Lake was the effect for programs that targeted teachers' instructional behaviors ( $E S=+0.33$ ) rather than the content of the programs. They noted, "Supplementing classroom instruction with well-targeted supplementary instruction is another strategy with strong evidence of effectiveness" (p. 481).

The use of computer software programs in increasing students' proficiency in reading and mathematics skills has been growing. However, the results have not been promising. Campuzano, Dynarski, Agodini, and Rall (2009) examined the effects of 10 reading and mathematics software products on student achievement. Their study tested the effectiveness of each software product by comparing the standardized test scores of students in classrooms using the products to those of students in similar classrooms not using the products. They reported one statistically significant effect for the six reading programs examined (LeapTrack ${ }^{\circledR}, 4^{\text {th }}$ grade). The estimated effect size was 0.09 , which they noted as the equivalent of moving a student from the $50^{\text {th }}$ to the $54^{\text {th }}$ percentile in reading achievement. None of the four math programs in the study demonstrated significant effects on students' achievement. These results, 
coupled with those presented above, give rise to the need to explore alternative structures and constructs for helping students to develop mathematics proficiency with word problems. In conjunction with the results emanating from Slavin and Lake (2008), researchers need to strive to change how teachers teach in order to produce the most promising outcomes for students' increased achievement. Thus we theorize a potential set of cognitive components in mathematics that focus on the reading demands of word-problem solutions-contextualized reading, vocabulary development, problem-solving structure comprehension, and concept development (Capraro \& Jofrion, 2006; Capraro \& Capraro, 2006; Rupley, 2006). Cognitive growth can be developed in and through both reading and mathematics. Mathematics educators have begun to recognize the importance and contribution of reading comprehension skills to students' mathematical success (Adams, 2003; Barton, Heidema, \& Jordan 2002).

\section{Perspectives on Previous Theories}

Several models have been suggested that account for the nexus of reading and mathematics. The National Council of Teachers of Mathematics (NCTM) proposed that students read to learn mathematics (NCTM, 2000). However, this proposal lacked the details to disaggregate the reading factors that specifically contribute to mathematical learning. In general, some factors have been identified from mathematics and reading research. There remains a need for research on the development of fully articulated mathematical instruction programs that (a) use what research has shown to be effective and (b) improve our future knowledge base-research that enables investigators to explore intervention efficacy in natural school settings (Cheung \& Slavin, 2005; Slavin \& Lake, 2008). The most promising models for using reading to improve mathematics strategies were expressed as including: a) application of reading for meaning, (b) vocabulary development, (c) chunking, (d) language usage, (e) inference, (f) reflection, $(\mathrm{g})$ didactics in multiple meanings, and $(\mathrm{h})$ using problems closely linked to students' real-world experiences (Powell, Fuchs, Fuchs, Cirino, \& Fletcher, 2009).

\section{Overview}

Two main objectives are outlined here that identify and assemble the shared constructs of reading and mathematics for the conceptual developmental of a theory of reading and mathematics for solving word problems. A feature of mathematical performance that has not been extensively studied is elementary students' solution 
of word problems, which is perhaps due to the fact that, " ... to solve a word problem, students must use text to identify missing information, construct a number sentence, and set up a calculation problem for finding the missing information" (Powell et al., 2009 , p. 2). We offer our assumptions about the shared constructs followed by sections theorizing the (1) refinement and evaluation components of Recognizing, Generating, and Attaining (RGA) that would have application to reading and the solution of word problems in elementary students; and (2) develop and refine the essential applied constructs of the theory. Our assumptions lay out the theoretical and research-based interrelationships of reading mathematics word problems by exploring and substantiating the cognitive components presented in Table 1: (1) Recognizing Higher Level Patterns of Text Organization, (2) Generating Patterns, and (3) Attaining a Goal-RGA Theory. These assumptions are to refine and construct the RGA cognitive components that could lead to an application that would increase elementary students' mathematical word problem-solving abilities.

\section{Table 1}

Three Broad Components of Cognition (Adapted from Rose, 2005) Reading Strategies Form the Constructs of Mathematics Strategies

RECOGNIZING HIGHER LEVEL PATTERNS OF TEXT ORGANIZATION OF WORD PROBLEMS

Reading Strategies

Semantics/Syntax/Word Identification \& Vocabulary Word order
Mathematics Strategies

Semantics/Syntax/Vocabulary of mathematical sentences

Order of operations, relational symbols, operators Fluency in mathematics

Fluency (Chunking)

Grouping of symbols (relational and operational) with numerical symbols for meaningful computation

GENERATING PATTERNS (ADOPTING SUCCESSFUL STRATEGIES FOR ACTING ON PATTERNS)

Comprehension

Predicting the organization of word problems

Understanding 1) information provided, 2) the expected or anticipated solution, and 3) sufficiency and necessity of the information provided

De-Coding written language to En-Coding into mathematics sentences-Building Internal Representation 
Translation of the written text into mathematical sentences based on semantics and syntax.

Restate the problem in own words-Able to retell the verbal story from the encoded mathematical sentences

ATTAINING A GOAL (KNOWING WHETHER OR NOT A GOAL IS REACHED)

Metacognition

Regulation of Text

Comprehension
Metacognition justification and re-solution strategies

Developing a simpler problem, able to characterize the problem using mathematical semantics and syn$\operatorname{tax}$

\section{The Dilemma}

Whether it is in mathematics, science, geography or other content areas, learning and applying knowledge requires the coordinated application of multiple reading strategies (Francis, Rivera, Lesaux, Kieffer, \& Rivera, 2006). Evidence suggests that many readers experience difficulty in cognitive processes such as making inferences, drawing conclusions, and predicting outcomes; those same processes that lead to successful solutions of word problems. Comprehension levels increase for elementary students when they are taught cognitive strategies through explicit instruction (Sencibaugh, 2007; Swanson, 1999).

Students' conceptual understandings were inextricably bound to their identifying words, understanding of vocabulary, and knowing the text structure (semantics and syntax) (Capraro, Capraro, \& Rupley, in press). Cognitive confusion results when students try to apply their general language meanings, which leads to inhibited reasoning. The content is obscured due to multiple meanings of familiar words being applied in a different context of understanding scientific usages (Rupley \& Slough, 2010; Slough \& Rupley, 2010). It is in the later elementary grades (third through fifth) where degrees of meaning begin to transition from literal, to inferential, and ultimately to conceptual learning. For students to become conceptual learners, they must move into inferential learning where they infer about mathematical ideas within the 
context of word problems, examine the cause and effect of events within word problems, and determine options for submitting possible approaches to obtaining a solution (Capraro \& Capraro, 2006).

Numerous studies of mathematical problems addressed the mental representation of the meaning of word problems; however, little of this work focused on the cognitive strategies students used to distinguish what was relevant from what was irrelevant (Kintsch, 1998; Kintsch \& Greeno, 1985; Koedinger \& Nathan, 2004; Moreau \& Coquin-Viennot, 2003). Reading in mathematics necessitates that one understands the meaning of the words within the context of the word problem. As children learn the vocabulary of mathematics, it is essential they either learn the meaning of new words that are not part of their oral vocabulary or understand the different meanings of words from those that they already know (Rupley, 2006).

Cognitive growth enables students more control over the complexity of word problem solving. Cognitive growth in solving mathematical word problems occurs in stages through representational filters (Capraro, Capraro, \& Cifarelli, 2007; Cifarelli, 1998) similar to the acquisition of language through language registers (Mehler et al., 2002). Many students have a tendency to use certain mathematical procedures without considering why the rules and procedures work. These students focus on the computational procedure rather than the conceptual understanding (Thompson, Phillip, Thompson, \& Boyd, 1994).

Cognitive strategies appear to mediate learning; therefore, changes that improve the individual cognitive strategy posed promise to influence the sophistication with which students solve complex word problems (Capraro et al., 2007). It is these cognitive strategies that are suspect when students demonstrate mathematical misconceptions (Capraro, Kulm, \& Capraro, 2005; Capraro, Kulm, Hammer, \& Capraro, 2002). One example would be when students are taught a reading strategy (Mehler et al., 2002) to literally translate word problems. For instance, in a typical problem like: "Ashley is three years older than Kenisha. Write an equation to show how old Ashley is relative to Kenisha's age," students are taught to literally translate the problem. Thus, Ashley is translated into $A=3$. Students are also taught that "than" sets up a comparison so students continue on the same side of the equal sign completing the sentence resulting in $\mathrm{A}=3+\mathrm{K}$, which is a correct representation of the solution. However, when the problem changes to, "Ashley is three years older than Kenisha. Write the equation to show Kenisha's age relative to Ashley's age" with the syntactic properties similar to the previous problem, but a semantic variation, students end up with the same equation $(A=3+K)$, but in this case, the representation is incorrect. However, students 
used the literal translation and were unaware of the syntactic difference, which should have resulted in the equation $(\mathrm{K}=\mathrm{A}-3)$.

In the three examples below we see the same problem, with each supporting the interrelationship of cognitive strategies founded upon reading comprehension and the solution of mathematical word problems (Capraro et al., 2007). In example 1, students using a literal translation scheme may arrive at one of these two possible incorrect solution representations.

Ex. 1 Quentin has some trading cards. Mohen has 3 times as many trading cards as Quentin. They have 36 trading cards in all. How many trading cards does Quentin have?
A) $3 X+36=X$
B) $X+3=36$

In example 2, the problem is changed to provide syntactic clues without the necessary semantic clues. So again students operating at a literal level find an inadmissible representation for the problem.

\section{Ex. 2 Mohen and Quentin have a total of 36 trading cards. Mohen has 3 times more trad-} ing cards than Quentin. How many trading cards does Quentin have?
A) $36=M 3$

However, in example three, the syntactic and semantic clues have been aligned to provide the necessary clues that help students' reason beyond the literal translation of word problems. The possible translation is still literal; however, the semantic and syntactic clues are aligned to allow discussion of these and for the teacher to model the solution process that can be used in the previous examples to move toward an implicit decoding scheme.

Ex. 3 Quentin has some trading cards but Mohen has 3 times more trading cards than Quentin. When you add their cards together they have 36 cards. How many trading cards does Quentin have?
A) $3 x+x=36$

As we have found in our own research (Rupley, 2006; Capraro \& Capraro, 2006), that as students transition from reading mathematical word problems for literal information, they begin to develop a mathematics language register. It is through this register that they begin to learn a cognitive process for decoding complex problems and understanding the inter-relationships of words to mathematical 
symbols (Rupley \& Nichols, in press). They begin to form the representational correlations between the word problem and mathematical constructs so they could express them in mathematical symbols (Capraro \& Joffrion, 2006; Capraro et al., 2007).

Children may translate English sentences into mathematical expressions, simply moving from left to right without awareness of syntactic and semantic relationships (Powell et al., 2009). For example, "three less than a number" was interpreted by many students as " 3 - X", which was really X - 3 since the words "less than" meant to subtract followed the 3 . Teachers must be aware of these literal translation schemes and address them through instruction (Lodholz, 1990). Evidence has suggested deeper cognitive reasons for students reversing variables or putting terms in the wrong order. The students in a particular study made an attempt to understand the problem, but were unable to represent their cognitive model symbolically (Capraro \& Yetkiner, 2008; MacGregor \& Stacey, 1993).

\section{Theory Constructs}

An essential feature of the theory we propose is the recognition of the inextricable relationship of the cognitive outcomes for both reading and mathematics. The constructs for each cognitive component of RGA are supported by research demonstrating benefits in reading and mathematics achievement and work together to help students analyze word problems conceptually. This theory, in application, we believe would better enable elementary students to begin to establish a learning foundation that enables them to think about problems less in terms of deriving an answer and more in terms of reasoning about underlying concepts, which is accessed through the reading and understanding of the text mathematically. This intent is pervasive throughout mathematics (Lave \& Wenger, 1991; Schoenfeld, 2006; Van Der Henst, Sperber, \& Politzer, 2002) and reading education (Fordham, 2006; Pressley, 2002a). The use of principles from cognitive science melds the shared components, skills, and understandings of these two into a theory of great potential for classroom application. 


\section{Recognizing Higher Level Patterns of Text Organization Cognitive Components (R) (Syntax/Semantics/Vocabulary \& Word Identification/ Fluency)}

The recognizing higher levels of text organization cognitive components we theorize will positively affect elementary students' achievement on word problems. In particular, we predict that Syntax, Semantics, and Word Identification/Fluency have individual and combined positive effects on the grades four and five students' achievement on word problems.

Research has shown us that syntax (e.g., verb, sentence structure, subject/ noun agreement), semantics (e.g., morphemes), and word identification and vocabulary (e.g., repeated readings, rhymes), as shown in Figure 1, are essential cognitive features in word problem solutions (Capraro et al., 2007) just as they are in reading comprehension and understanding (Pressley, 2002a; Smagorinsky, Cook, \& Reed, 2005). Reasoning capabilities for these reading skills support and reinforce conceptualization of mathematical word problems. Littlefield and Rieser's (1993) semantic features model of discriminating information advanced the credibility of the paramount importance of these features, and presented evidence that this model fits the discrimination performance of students who are successful at mathematics as well as those who are less successful. Their model demonstrated how successful students analyze the problem text and questions into semantic units, including the actions, agents (persons/things carrying out the action), objects acted upon (these typically correspond to the units of measure), as well as the time and place of actions. Successful students identify relevant information by searching the problem text for information, trying to match the values of semantic features requested in the question with those in the problem text. In contrast, less successful mathematics students were significantly more likely to base their discriminations on surface level aspects of the text such as the position of information within the problem statement (e.g., consistently selecting as relevant the first and last numbers). This strategy is almost identical to those employed by readers who have good word recognition skills but lack a cognitive understanding that the purpose of reading is comprehension. They are dealing with the surface or text level features and failing to connect with their prior knowledge to get meaning (Afflerbach, Pearson, \& Paris, 2008; Jetton, Rupley, \& Willson, 1995). 


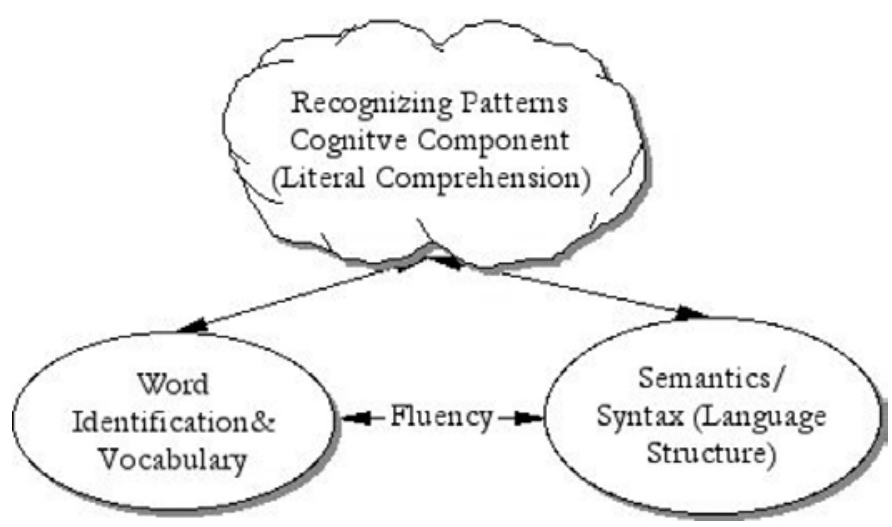

Fig. 1: Recognizing patterns

\section{Example of Pedagogical Features of the Recognizing Patterns Cogni- tive Component Are Listed Below:}

Modified cloze procedures: where students write the correct word in each blank space, solve the word problem and discuss among themselves how the conceptualization was determined by the words/numbers used in the blanks. Such a feature focuses on both the syntax and the semantics of the text and the meaning features and graphic features of their word/number choices. The word choices must not only be correct syntactically, but must also make sense (semantics) in the conceptualization of the mathematical problem. For example: The boys went to the store to buy candy. Each boy wanted to buy some large candy bars. They had $\$ 10.00$ to buy their candy. The candy bars were two for or for one candy bar. The most candy bars they can buy is . The fewest number of candy bars they can buy is

Classification: is associated with all three language features (syntax, semantics, word identification/vocabulary) and can be used to introduce and practice new mathematical conceptual words and to reinforce successful comprehension. A highly successful technique for increasing word-identification abilities that we know should generalize to mathematics is to encourage students individually and in small groups to learn words by arranging them in a word sort. A word sort is a method of sorting word cards into various mathematical categories (such as sum, how many, total, all together). 
Semantic Clues Categories: enable readers to better understand and comprehend what they are reading in mathematics. These clue categories are essential for conceptualization in mathematics (Mayer, \& Hegarty,1996). Johnson and Pearson (1984) classified the major kinds of semantic clues available to readers. A modified listing applicable to mathematics follows:

- $\quad$ Signal words in mathemathics texts are words such as is, are, and combined. Words such as these are often used to alert the reader about equivalencies or operations.

- Synonyms and antonyms. When students encounter unknown mathematical words they can use either synonyms or antonmyns (e.g., subtraction is an antonmyn of addition) with their zone of proximal development to support their problem-solving development.

- Summary statements. Based on connected mathematical story information, there may be multiple solutions, which are defensibile based upon cognitive reasoning.

Morphemes: are essential to understanding text and enabling the conceptualization of mathematical word problems. The Recognizing Patterns cognitive component focuses on teaching students to learn and understand the functions of both bound and free morphemes. Affixes (prefixes, suffixes, and inflectional endings) are bound morphemes that must be attached to a free morpheme or base word. Some common prefixes and suffixes (affixes), base words, and root words can help students learn the meanings of many words encountered in mathematics, (Goldfield \& Snow, 1999). For example, if students learn just the four most common prefixes in English (un-, re-, in-, dis-), they will have important clues about the meaning of about two thirds of all English words that have prefixes (Armbruster \& Osborn, 2001).

Word Identification \& Fluency: Researchers (Rasinski, Rupley, \& Nichols, in press; Samuels \& Flor, 1997) have identified effective techniques related to repeated oral reading that will be integrated into the development of the Recognizing Patterns cognitive component: (1) students read and reread a text a certain number of times or until a certain level of fluency is reached (generally 80 to 100 words per minute are required to chunk text into comprehensible units for processing); (2) four re-readings are generally sufficient for most students; and (3) oral reading practice can be increased through the use of audiotapes, tutors, and peer guidance. Poetry, rhymes, and songs are especially well suited to fluency practice because they are often short, repetitive, and they contain rhythm, rhyme, and meaning, and can incorporate the use of multiple input channels for processing of text. Two examples showing slightly different levels of mathematics: 
Rain, rain go away.

It rained 5 inches yesterday.

Rain, rain go away.

It rained 6 more inches again today.

Rain, rain go away.

It will rain again tomorrow,

4 more inches is what they say.

Rain, rain go away.

If this is so it will have rained inches in just three days.

I will never get to play.

It will be averaging

inches of rain a day.
Rain, rain go away.

It rained 5 1/4 inches yesterday

Rain, rain go away.

It rained 3.5 more inches today.

Rain, rain go way.

It will rain again tomorrow,

$33 / 8$ more inches they say.

Rain, rain go away.

If this is so it will have rained inches in just three days.

I will never get to play.

It will be averaging

inches of rain a day.

\section{Generating Patterns Cognitive Components (G)}

The Generating Patterns Cognitive Components we theorize will positively affect elementary grade students' achievement on word problems. In particular, we predict that Story Schema, Comprehension, and Summarization will have individual and combined positive effects on the students' achievement on word problems.

A story schema is a set of expectations about how stories are usually organized (Gordon \& Braun, 1983). An internal organization of story knowledge enables readers to process print by retaining story information in memory (see Figure 2) until it makes sense and adding more information as they read. A reader's story schema also is important in that it forms a template for recalling what was read. While narrative materials follow a traditional story structure, expository writing is organized differently. Most content texts are written in an expository/informational style, which results in text that is subject structured, compact, detailed, and explanatory in nature. Mathematical word problem schema is characterized by three basic mathematical components embedded within them (Teubal, 1975): the verbal formulation; underlying mathematical relations; and the symbolic mathematical expression. Word problems can be further analyzed by examining their linguistic properties, their logicomathematical properties, or their symbolic representations. Linguistic properties included such variables as the number of words in the problem or the mean sentence length (Lepik, 1990). The logico-mathematical properties can be classified in numerous ways, but one scheme is to classify the quantities in the problem into known quantities, the values that needed to be found, and values that may need to be found as intermediate stages of the problem (Verschaffel, Greer, \& De Corte, 2000). 
Background knowledge, including purposes, has an overriding influence upon the reader's development of meaning (Gersten, Fuchs, Williams, \& Baker, 2001). Reading comprehension involves activating, focusing, maintaining, and refining of ideas toward developing interpretations that are plausible (Okolo, Englert, Bouck, \& Heutsche, 2007). Thus successful comprehension is an interrelated activation of multiple mental processes (Pressley, 2002b) that originate with the connection of prior knowledge with the purpose of the reading act, which are then interconnected and result in comprehension.

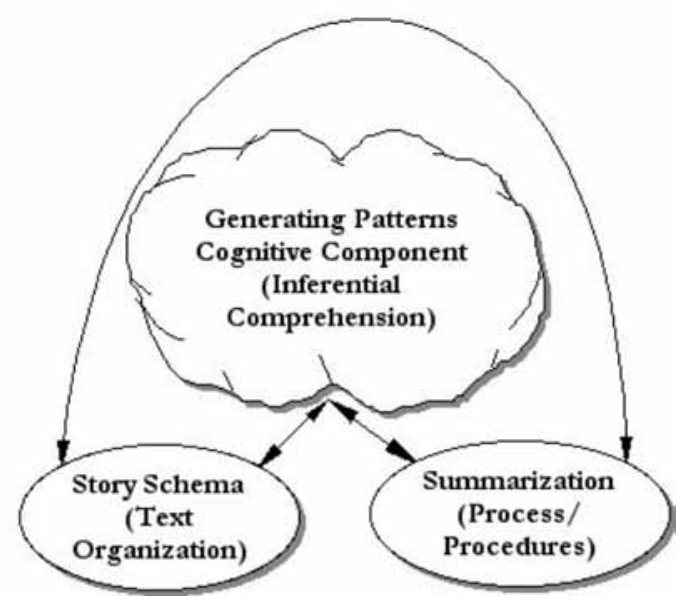

Fig. 2: Generating patterns

In addition, there is a sense in which the reader's comprehension involves two other facets: the reader knowing (either tacitly or consciously) that his or her interpretations for a text were plausible, interconnected, and completely made sense, and, ideally, the reader's evaluation of the transfer value of any acquired understanding. We can view background knowledge as an individual's experiential and cognitive capabilities for (1) written text (word recognition, concept of print, understanding of word order, and understanding of word meanings), as well as (2) the content of what is being read, and (3) how text is organized (Alexander \& Jetton, 2000). Activating prior knowledge is especially important in mathematics word problems: “. . ., an effective reader has a clear understanding of mathematical concepts, how they build on one another, and how they are related" (Barton \& Heidema, 2002, p. 11). 


\title{
Examples of Pedagogical Features of the Generating Patterns Cognitive Component Are Listed Below:
}

\author{
Story Schema: (Representation of Reading Plot and Mathematics Plot Relation- \\ ships) Starter Event, Inner Response, and Action (Reading) Initial State (Mathematics): \\ Billy hoped to get a bike for his birthday. But he didn't so he decided to make a plan \\ to buy one for himself. He decided to work odd jobs around the neighborhood for 7 \\ days to save enough money to buy his bike. Outcome (Reading) Goal State (Math- \\ ematics). On Monday he earned $\$ 2.00$, on Tuesday he earned $\$ 4.00$, on Wednesday he \\ earned $\$ 8.00$, and Thursday he earned $\$ 16.00$, and on Friday he earned $\$ 32.00$. Reac- \\ tion (Reading), Legal Problem-Solving Operators (Mathematics). Did he have enough \\ money to buy a bike for $\$ 250.00$ ? Did he have any money left over?
}

Comprehension: in our theory, comprehension is connected to the two critical components for understanding mathematical word problems (Neufeld, 2005)-prior knowledge and purpose(s) for reading. Questions that have answers within the text information are explicit and referred to as the in-the-book category. This type of question can be used to guide students to realize when the answer is either (1) explicitly stated in the text in one or two sentences (There were 31 ducks on the lake. When the dog barked 10 flew off, how many are left?) or (2) explicitly stated in the text but requires putting together information from several parts. (There were 31 ducks on the lake. Because if was getting colder more ducks were flying south for the winter and flew over the lake. The lake was large and 10 more ducks landed on it. The ducks that landed scared off 3 ducks that were already there. Another flock of ducks flew over and 29 landed on the lake. The farmer who lived close to the lake had a tractor that made a loud noise when he drove it. When he went close to the lake 8 ducks flew off. How many ducks are still on the lake?). Readers must think and search for the conceptual information necessary to understand the word problem when working with upper-elementary and middle-school students by including strategies for identifying information in terms of their prior knowledge of text structure (Raphael, 1988; Raphael \& Au, 2005). Knowledge of text structure will help students understand how information is organized and how this knowledge helps to conceptualize mathematics.

Summarizing: Readers who can effectively summarize information can also sort through large pieces of text, distinguish important from unimportant ideas, and bring the ideas together so that the new text represents the original (Capraro \& Yetkiner, 2008). The ability to summarize appears to be developmental (Rupley \& Willson, 1997). A summary, such as a paraphrase, is a variation of an original passage in one's own words. Summary strategies for reading and mathematics are of paramount 
importance in reading and conceptualizing mathematical word problems. In reading, the summary demands that readers (1) determine what is important, (2) condense the information, and (3) then put it in their own words. The summary process in conceptual mathematics is identical; however, "putting it in their own words" is deriving from the story the information for solution of the problem. Salient features of summarization include: (1) Identifying the problem in their own words and representing it through writing, drawing, or making a table. (2) Determining the main ideas and connecting them together in a webbing activity, semantic features analysis, or writing activity. (3) Reading and eliminating from the mathematical word problem redundant and unnecessary information. And (4) Remembering what they read by answering summary questions.

\section{Attaining a Goal Cognitive Components (A)}

The Attaining a Goal Cognitive Components will positively influence elementary students' achievement on solving word problems. In particular, we predict that Text Organization and Regulated Comprehension of Text have individual and combined positive effects on the students' achievement in solving word problems.

Competent readers monitor their comprehension and know when the process is breaking down (Cross \& Paris, 1988). This monitoring of comprehension has been deemed metacognition (See Figure 3). We have learned over the past few decades that good readers are aware of how they construct meaning and apply corrective strategies when they are not constructing meaning (Zimmerman, 1989). Metacognition requires knowing how to achieve the goal that has not been accomplished, as well as knowing when a goal has been reached. The other component of goal attainment is regulation of text comprehension. Regulation of text comprehension is the incorporation or translation of multiple sentences into knowledge units on which they can take some action. In brief, the issue is one of resource allocation during cognitive activity and problem solving.

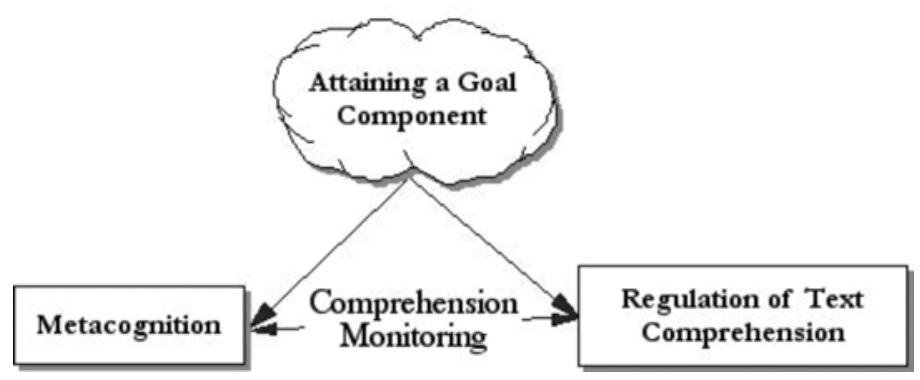

Fig. 3: Attaining goals 


\section{Metacognition}

Metacognition in the reading domain is a support for working memory in the conceptualization and solution of mathematical word problems. Working memory (where thinking "gets done") receives its contents from two sources, the sensory buffer and long-term memory. The most important aspect of working or short-term memory (STM) is its limited capacity. In general humans can only keep about seven "chunks" of information in STM, and operate on them (Miller, 1950 as cited in Schoenfeld, 2006). Metacognitive strategies provide a buttress for the memory process by feeding back into working memory of mathematical conceptual knowledge that sustains continued progress toward obtaining a solution.

In a comprehensive synthesis of metacognitive research in reading, Pressley (2002b) noted the following: (1) minimal effort is needed to decode words, which frees up a great deal of cognitive capacity for comprehension, for both words and ideas that are represented by phrases, sentences, and paragraphs; (2) cognitive capacity is put to effective use to metacognitively focus on knowing that comprehension is built by relating what is read to prior knowledge; (3) metacognition thus facilitates prediction by the reader about what might be coming up in the text and summarize what is being read; and (4) metacognition used by readers alerts them to when ideas are confusing and how to respond to fix-up strategies, such as rereading, diagramming, searching for patterns, and identifying key concepts carrying words.

Organization of Contents of Memory (Schoenfeld, 1992), taken from Silver (2000), represents the metacognitive, reciprocal relationship of mathematical problem solutions and reading components, which are the stimuli represented by the visual sensory buffer. Reading the word problem activates meta-level processes and mental representations leading to mathematics knowledge and metacognitive knowledge to monitor conceptualization of word problems that lead toward continuous progress to solution of the word problem.

Readers, therefore, must have the ability to monitor their comprehension and know when they have achieved their purposes for reading, when they understand and do not understand what they are reading, and how to correct and regulate their comprehension of text (Sencibaugh, 2007). The same attributes are necessary for conceptualization and solution of mathematical word problems. The instructional components emanating from our theory could be applied to guide elementary students to become aware of what they are doing and why they are doing it. In addition, it supports the development of strategies that model how to check, monitor, and test hypotheses. It provides for them cognitive strategies to monitor their understanding 
of mathematical word problems and employ and activate fix-up strategies when understanding breaks down.

\section{Example of Pedagogical Features of the Attain a Goal Cognitive Component Are Listed Below:}

Text Organizations: analysis of the structure of the text is a means for monitoring comprehension efficacy. Strategies for analysis of text organizations include the following: (1) Draw a diagram or a map of the word problem if it involves distance and/ or places. (2) Find a pattern or make a model by skipping around in the text to create a model of the main idea: this may require going back to some information or to read the text quickly the first time and skip ahead to add to the model. (3) Work backwards if the word problem is asking about what happened first or at the beginning of the word problem.

Regulation of Text Comprehension: Those students who have good comprehension are also active and engaged readers (Connor, Morrison, \& Petrella, 2004). These readers relate ideas in text to their prior knowledge, construct images, and generate summaries. They do a lot of monitoring with discernment of understanding during reading, enabling them to establish effective recognition of how they process the text. Such here-and-now cognition in the form of active discernment of meaning is always being generated as the competent reader reads with such awareness. Strategies that serve these purposes are: (1) Solve a simpler problem by transforming a difficult or complicated word problem into a simpler problem with similar steps and operations; then, this is transferred to conceptualizing the complicated word problem. (2) "Guess and check" enables the approximation of a solution for a word problem and activates prior knowledge for the elaboration of the process to be applied to the original problem and construct a model for solution. (3) Logical reasoning is used to determine the key concept intended to be conveyed through the "word" in the mathematical word problem.

\section{Discussion}

The theory of integrating reading and mathematical constructs represents a unique and logical synthesis across extant reading and mathematics literature. The nexus of reading to learn and the acquisition of mathematics knowledge is a relatively unexplored construct in the elementary grades where reading and mathematical 
skills lead to either the success or failure of each in later grades. While there may be many other possible constructs on which to build mathematical learning, none seem so plausible as one that combines the literature across reading and mathematics. This construct makes use of ideas originally suggested in the cognitive sciences that propose learning that scaffolds across subject areas increases the rigor and provides richer contexts from which deeper understandings can be fostered.

The integration theory assembles a set of constructs in reading and mathematics that focus on the nexus of reading and mathematics as complementary, interconnected, and interdependent. Mathematics content devoid of context is useless (Adams, 2003). The real-world context for solving mathematical word problems is conveyed in writing, spoken language, and through stories told from one person to another (Boaler, 1999). Mathematical language follows a structure parallel to that learned for reading. Context gives meaning to written words and mathematical sentences. Children must be taught to intertwine reading and mathematical cognitive strategies to make meaning of word problem-solving events. The real-world context for mathematics is conveyed in writing, speaking, and through stories. These basic communication conditions are the link for understanding mathematical language.

It is critical for elementary students to know and understand mathematical language and to develop facility with recognizing patterns within this language. Mathematics is often taught and uniformly assessed, embedded within dense textual presentations requiring facility with language structure, fluency, and vocabulary. This overarching strategy is important for translating word problems into mathematical symbols for selecting a suitable algorithm. How do children make sense of contextualized mathematical word problems? Some have hypothesized a key word strategy similar to sight vocabulary lists in reading, while others support a decoding strategy, yet others support a broad contextualized reading vocabulary accompanied by strong mathematical conceptualizations and accurate procedural knowledge. One strategy incorporates mathematics literature books to create dynamic and interactive learning environments (Bintz \& Moore, 2002; Capraro \& Capraro, 2006). While some argue that teacher and instructional characteristics yield promising factors for improving mathematics achievement (Meijnen, Lagerweij, \& de Jong, 2003), we suggest an amalgam of strategies synthesized into the cognitive strategy referred to as generating patterns. The use of this cognitive strategy that builds on recognizing patterns while adding well-known components of predicting, decoding and encoding, building internal representations, and restating serve to create the intellectual structures to bridge into the final hypothesized cognitive strategy. 
The capstone of our theoretical model is the cognitive strategy of Goal Attainment. Goal attainment reflects the ability of students to know what to do and how to do it. In today's society many students have reading and mathematical difficulties. Often arithmetic computation is used as a proxy measure of mathematics learning when in fact naked computation is a poor proxy for mathematical ability and poorly correlated to current trends in high stakes assessment. Comorbidity (mathematics and reading difficulties) compounds issues related to mathematics learning when students are expected to comprehend nuances in either spoken or written communication (Bos et al., 2003). Therefore, students encounter learning conditions that are not aligned with developing and applying metacognitive strategies. The lack of development of the ability to introspectively exam one's own thinking becomes a barrier to being able to make meaningful connections between and among the cognitive strategies.

We believe our synthesis of the existing literature and the resulting analytical and theoretical framework can serve to stimulate introspective and reflective thinking regarding the inter-relationships of reading and mathematical word problem solutions in the elementary grades. In addition, components of the theory can provide researchers with a starting point to pursue more in-depth aspects of the shared features of the cognitive components between reading and mathematics.

\section{References}

Adams, T. L. (2003). Reading mathematics: More than words can say. Reading Teacher, 56, 786-795.

Afflerbach, P., Pearson, P., \& Paris, S. G. (2008). Clarifying differences between reading skills and reading strategies. The Reading Teacher, 61, 364-373.

Alexander, P. A., \& Jetton, T. L. (2000). Learning from text: A multidimensional and developmental perspective. In M. L. Kamil, P. B. Mosenthal, P. D. Pearson, \& R. Barr (Eds.), Handbook of reading research (Vol. 3, pp. 285-310). Mahwah, NJ: Erlbaum.

Armbruster, B. B., \& Osborn, J. (2001). Putting reading first: The research building blocks for teaching children to read. Washington, D.C: National Institute of Child Health and
Human Development and the U.S. Department of Education.

Baroody, A. J. (1989). One point of view: Manipulatives don't come with guarantees. Arithmetic Teacher, 37, 4-5.

Barton, M. L., \& Heidema, C. (2002). Teaching reading in mathematics ( $2^{\text {nd }}$ ed.). Aurora, CO: Mid-continent Research for Education and Learning.

Barton, M. L., Heidema, C., \& Jordan, D. (2002). Teaching reading in mathematics and science. Educational Leadership. 60, 24-28.

Bintz, W. P., \& Moore, S. D. (2002). Using literature to support mathematical thinking in middle school. Middle School Journal, 34(2), 25-32. 
Boaler, J. (1999). Participation, knowledge and beliefs: A community perspective on mathematics learning. Educational Studies in Mathematics, 40, 259-281.

Bos, W., Lankes, E., Prenzel, M., Schwippert, K., Walther, G., \& Valtin, R., et al. (2003). Welche fragen konnen aus einer gemeinsamen interpretation der befunde aus PISA and IGLU fundiert beantwortet werden? [To which questions does a combined interpretation of the results yielded by both PISA and IGLU provide well-grounded answers?]. Zeitschrift fur Padagogik, 49(2) 198-212.

Campuzano, L., Dynarski, M., Agodini, R., \& Rall, K. (2009). Effectiveness of reading and mathematics software products: Findings from two student cohorts (NCEE 2009-4041). Washington, DC: National Center for Education Evaluation and Regional Assistance, Institute of Education Sciences, U.S. Department of Education.

Capraro, M. M., Capraro, R. M., \& Cifarelli, V. V. (2007). What are students thinking as they solve open-ended mathematics problems? In D. K. Pugalee, A. Rogerson, \& A. Schnick (Eds.), Proceedings of the ninth international conference of Mathematics Education in a Global Community. Charlotte, NC.

Capraro, M. M., \& Joffrion, H. (2006). Algebraic equations: Can middle-school students meaningfully translate from words to mathematical symbols? Reading Psychology, 27, 147-164.

Capraro, M. M., Kulm, G., \& Capraro, R. M. (2005). Middle grades: Misconceptions in statistical thinking. School Science and Mathematics Journal, 105, 165-174.

Capraro, R. M., \& Capraro, M. M. (2006). Are you really going to read us a story? Learning geometry through children's mathematics literature. Reading Psychology, 27, 21-36.

Capraro, R. M., Capraro, M. M., \& Rupley, W. (in press). Reading enhanced word problem solving (REPS): A theoretical model. European Journal of Psychology of Education.

Capraro, R. M., Kulm, G., Hammer, M., \& Capraro, M. M. (2002). The origin and persistence of misconceptions in statistical thinking. In D. S. Mewborn, P. Sztajn, D. Y. White, H.
G. Wiegel, R. L. Bryant, \& K. Nooney (Eds.), Proceedings of the twenty-fourth annual meeting of the North American Chapter of the International Group for the Psychology of Mathematics Education, 3, 1339-1340. Columbus, OH: ERIC Clearinghouse for Science, Mathematics, and Environmental Education.

Capraro, R., M., \& Yetkiner, Z. E. (2008). Teacher's role in developing representational fluency in middle grades. In G. Kulm, (Ed.), Teacher knowledge and practice in middle grades mathematics (pp. 273-286). Rotterdam, The Netherlands: Sense.

Cheung, A., \& Slavin, R. E. (2005). Effective reading programs for English language learners and other language minority students. Bilingual Research Journal, 29, 241-267.

Cifarelli, V. V. (1998). The development of mental representations as a problem solving activity. Journal of Mathematical Behavior, 17, 239-264.

Clements, D. H., \& McMillen, S. (1996). Rethinking concrete manipulatives. Teaching Children Mathematics, 2, 270-279.

Connor, C. M., Morrison, F. J., \& Petrella, J. N. (2004). Effective reading comprehension instruction: Examining child $\mathrm{x}$ instruction interactions. Journal of Educational Psychology, 96, 682-698.

Cross, D. R., \& Paris, S. (1988). Developmental and instructional analyses of children's metacognition and reading comprehension. Journal of Educational Psychology, 80, 131-143.

Driscoll, M. J. (1983). Research within reach: Elementary school mathematics and reading. St. Louis, MO: CEMREL.

Fennema, E. (1972). The relative effectiveness of a symbolic and a concrete model in learning a selected mathematics principle. Journal for Research in Mathematics Education 3, 233-238.

Fordham, N. W. (2006). Crafting questions that address comprehension strategies in content reading. Journal of Adolescent \& Adult Literacy, 49, 390-396.

Francis, D. J., Rivera, M., Lesaux, N., Kieffer, M., \& Rivera, H. (2006). Practical guidelines for the education of English language learners: 
Research-based recommendations for instruction and academic interventions. Portsmouth, NH: RMC Research Corporation, Center on Instruction.

Fuson, K, C., Carroll, W. M., \& Landis, J. (1996). Levels in conceptualizing and solving addition and subtraction compare word problems. Cognition and Instruction, 14, 345-371.

Gersten, R., Fuchs, L. S., Williams, J. P., \& Baker, S. (2001). Teaching reading comprehension strategies to students with learning disabilities: A review of research. Review of Educational Research, 71, 279-320.

Goldfield, B. A., \& Snow, C. E. (1999). Individual differences in language acquisition. In J. Berko (Ed.), The development of language ( $4^{\text {th }}$ ed.) (pp. 299-324). Upper Saddle River, NJ: Merrill/Prentice Hall.

Gordon, C. J., \& Braun, C. (1983). Using story schema as an aid to reading and writing. The Reading Teacher, 2, 116-121.

Harris, K. R., \& Pressley M. (1991). The nature of cognitive strategy instruction: Interactive strategy construction. Exceptional Children, 57, 392-404.

Jetton, T., Rupley, W. H., \& Willson, V. L. (1995). Comprehension of narrative and expository texts: The role of content, domain, discourse, and strategy knowledge. In K. Hinchman, D. J. Leu, \& C. K. Kinzer (Eds.) Perspectives on literacy research and practice. $44^{\text {th }}$ Yearbook of the National Reading Conference. Chicago: NRC, 197-204.

Johnson, D. D., \& Pearson, P. D. (1984). Teaching reading vocabulary ( $2^{\text {nd }}$ ed.). New York: Holt, Rinehart \& Winston.

Kintsch, W. (1998). Comprehension: A paradigm for cognition. Cambridge, UK: University Press.

Kintsch, W., \& Greeno, J. G. (1985). Understanding and solving word arithmetic problems. Psychological Review, 92, 109-129.

Koedinger, K. R., \& Nathan, M. J. (2004). The real story behind story problems: Effects of representations on quantitative reasoning. The Journal of the Learning Sciences, 13, 129-164.
Lave, J., \& Wenger, E. (1991). Situated learning: Legitimate peripheral participation. Cambridge, MA: University Press.

Lepik, M. (1990). Algebraic word problems: Role of linguistic and structural variables. Educational Studies in Mathematics, 21, 83-90.

Littlefield, J., \& Rieser, J. J. (1993). Semantic features of similarity and children's strategies for identification of relevant information in mathematical story problems. Cognition \& Instruction, 11, 133-188.

Lodholz, R. (1990). The transition from arithmetic to algebra. In E. L. Edwards, Jr. (Ed.), Algebra for everyone (pp. 24-33). Reston, VA: National Council of Teachers of Mathematics.

MacGregor, M., \& Stacey, K. (1993). Cognitive models underlying students' formulation of simple linear equations. Journal for Research in Mathematics Education, 24, 217-232.

Mayer, R. E., \& Hegarty, M. (1996). The process of understanding mathematical problems. In R. J. Sternberg \& T. Ben-Zeev (Eds.), The nature of mathematical thinking (pp. 29-53). Mahwah, NJ: Erlbaum.

Mehler, J., Jusczyk, P., Lambertz, G., Halsted, N., Bertoncini, J., \& Amiel-Tison, C. (2002). A precursor of language acquisition in young infants. In G. T. M. Altman (Ed.), Psycholinguistics: Critical concepts in psychology. New York: Taylor \& Francis.

Meijnen, G. W., Lagerweij, N. W., \& de Jong, P. F. (2003). Instruction characteristics and cognitive achievement of young children in elementary schools. School Effectiveness and School Improvement, 14, 159-187.

Moreau, S., \& Coquin-Viennot, D. (2003). Comprehension of arithmetic word problems by fifth-grade pupils: Representations and selection of information. British Journal of Educational Psychology, 73, 109-121.

Mullis, I. V. S., Martin, M. O., \& Foy, P. (2008). TIMSS 2007 international mathematics report: Findings from IEA's Trends in International Mathematics and Science Study at the fourth and eighth grades. Chestnut Hill, MA: TIMSS \& PIRLS International Study Center, Boston College. 
Nagy, W., Berninger, V., Abbott, R., Vaughan, K., \& Vermeulen, K. (2003). Relationship of morphology and other language skills to literacy skills in at-risk second readers and at-risk fourth-grade writers. Journal of Educational Psychology, 95, 730-742.

Nagy, W. E., \& Scott, J. A. (2000). Vocabulary processes. In M. L. Kamil, P. Mosenthal, P. D. Pearson, \& R. Barr (Eds.), Handbook of reading research (Vol. III. pp. 269-284). Mahwah, $\mathrm{NJ}$ : Earlbaum.

National Assessment Governing Board. (2009). 2009 Nation's Report Card in Mathematics Reveals No Change at $4^{\text {th }}$-Grade, But New High for 8th-Grade Score. News Release.

National Council of Teachers of Mathematics. (2000). Principles and standards for school mathematics. Reston, VA: Author.

Neufeld, P. (2005). Comprehension instruction in content area classes. The Reading Teacher, 59, 302-312.

Okolo, C. M., Englert, C. S., Bouck, E. C., \& Heutsche, A. M. (2007). Web-based history learning environments: Helping all students learn and like history. Intervention In School And Clinic, 43, 3-11.

Organisation for Economic Cooperation and Development. (2006). Assessing scientific, reading and mathematical literacy: $A$ framework for PISA 2006. Paris: Author.

Powell, S. R., Fuchs, L. S., Fuchs, F. D., Cirino, P. T., \& Fletcher, J. M. (2009). Do word problem features differentially affect problem difficulty as a function of students' mathematics difficulty with and without reading difficulty? Journal of Learning Disabilities, 42, 99-110.

Pressley, M. (2002a). Comprehension strategies instruction: A turn-of-the-century status report. In C. C. Block \& M. Pressley (Eds.), Comprehension instruction: Research-based best practices (pp. 11-27). New York: Guilford.

Pressley, M. (2002b). Metacognition and selfregulated comprehension. In A. E. Farstrup \& S. Samuels (Eds.), What research has to say about reading instruction (pp. 291-309). Newark, DE: International Reading Association.
Pressley, M., Levin, J. R., \& Delaney, H. D. (1982). The mnemonic keyword method. Review of Educational Research, 52, 61-91.

Raphael, T. E. (1986). Teaching question answer relationships, revisited. Reading Teacher, 39, 516-522.

Raphael, T. E., \& Au, K. H. (2005). QAR: Enhancing comprehension and test taking across grades and content Areas. The Reading Teacher, 59, 206-221.

Rasinski, T., Rupley, W. H., \& Nichols, W. D. (in press). Synergistic phonics and fluency instruction: The magic of rhyming poetry! New England Journal of Reading.

Rose, D. H. (2005). Cognition and learning: Meeting the challenge of individual differences. Retrieved August 12, 2008, from http:// www.cast.org/index.html

Rupley, W. H. (2006). Reading and mathematics: Introduction. Reading Psychology: An International Journal, Special Issue on Reading and Mathematics, 27, 87-89.

Rupley, W. H., \& Nichols, W. D. (in press). Matching instructional design with vocabulary instruction. Reading Horizons.

Rupley, W. H., \& Slough, S. W. (2010). Building prior knowledge and vocabulary in science in the intermediate grades: Creating hooks for learning. Literacy Research and Instruction, 49, 99-112.

Rupley, W. H., \& Willson, V. L. (1997). The relationship of reading comprehension to components of word recognition: Support for developmental shifts. Journal of Research and Development in Education, 30, 255-260.

Samuels, S. J., \& Flor, R. F. (1997). The importance of automaticity for developing expertise in reading. Reading \& Writing Quarterly, 13, 107-121.

Schoenfeld, A. H. (1992). On paradigms and methods: What do you do when the ones you know don't do what you want them to? Issues in the analysis of data in the form of videotapes. The Journal of The Learning Sciences, 2, 179-214.

Schoenfeld, A. H. (2006). Learning to think mathematically: Problem solving, metacognition, and sense making in mathematic semantics. In D. A. Grouws (Ed.), Handbook 
of research on mathematics teaching and learning. New York: Macmillan.

Sencibaugh, J. M. (2007). Meta-analysis of reading comprehension interventions for students with learning disabilities: Strategies and implications. Reading Improvement, 44(1), 6-22.

Silver, E. A. (2000). Improving mathematics teaching and learning: How can principles and standards help? Mathematics Teaching in the Middle School, 6, 20-23.

Slavin, R. E., \& Lake, C. (2008). Effective programs in elementary mathematics; A best-evidence synthesis. Review of Educational Research, 78, 427-515.

Slough, S. W., \& Rupley, W. H. (2010). Recreating a recipe for science instructional programs: Adding learning progressions, scaffolding, and a dash of reading variety. School Science and Mathematics Journal, 110, 352-362.

Smagorinsky, P., Cook, S. L., \& Reed, P. M. (2005). The construction of meaning and identity in the composition and reading of an architectural text. Reading Research Quarterly, 40(1) 35-52.

Sowell, E. J. (1989). Effects of manipulative materials in mathematics instruction. Journal for Research in Mathematics Education, 20, 498-505.

Suydam, M. N. (1986). Research report: Manipulative materials and achievement. Arithmetic Teacher 33, 10, 32.
Suydam, M. N., \& Higgins, J. L. (1976, September). Review and synthesis of studies of activity-based approaches to mathematics teaching. Final report, NIE Contract No. 400-75-0063. Columbus, OH: Information Analysis Center for Science, Mathematics and Environmental Education.

Swanson, H. L. (1999). Instructional components that predict treatment outcomes for students with learning disabilities: Support for a combined strategy and direct instruction model. Learning Disabilities Research and Practice, 14, 129-140.

Teubal, T. N. (1975). Verbal cues as an interfering factor in verbal problem solving. Educational Studies in Mathematics, 6, 41-51.

Thompson, A. G., Phillip, R. A., Thompson, P. W., \& Boyd, B. (1994). Calculational and conceptual orientations in teaching mathematics. In D. Achele \& A. F. Coxford (Eds.), Professional development of teachers of mathematics (pp. 79-92). Reston, VA: National Council of Teachers of Mathematics.

Van Der Henst, J., Sperber, D., \& Politzer, G. (2002). When is a conclusion worth deriving? A relevance-based analysis of indeterminate relational problems. Thinking \& Reasoning, 8, 1-20.

Verschaffel, L., Greer, B., \& De Corte, E. (2000). Making sense of word problems. Educational Studies in Mathematics, 42, 211-213.

Zimmerman, B. J. (1989). A social cognitive view of self-regulated academic learning. Journal of Educational Psychology, 81, 329-339. 


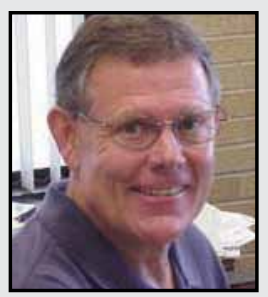

William H. Rupley, Professor in the Department of Teaching, Learning and Culture, and Affiliate Faculty Member in Educational Psychology, University Regent's Fellow, and Distinguished Research Fellow, Texas A\&M University. He is the Editor-in-Chief of Reading Psychology: An International Journal.

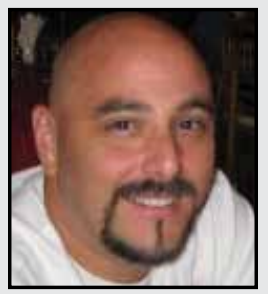

Robert Capraro, Professor of Mathematics Education in the Department of Teaching, Learning and Culture, University Regent's Fellow, and Co-Director of the Aggie STEM Center at Texas A\&M University. He is the past associate editor of the American Educational Research Journal-Teaching Learning and Human Development, associate editor of School Science and Mathematics, and Middle Grades Research Journal.

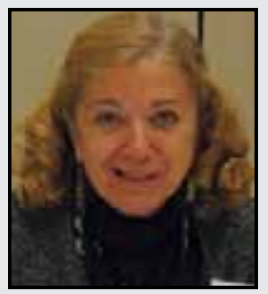

Mary Margaret Capraro, Associate Professor of Mathematics Education at Texas A\&M University and Co-Director of the Aggie STEM Center. She was previously employed with the Miami Dade County Schools as both a teacher and an assistant principal. She has over 70 publications, and 55 national and international presentations. Her research interests include teacher knowledge and preparation in mathematics education and student understanding of mathematical concepts.

LINK TO:

http://directory.cehd.tamu.edu/view.epl?nid=w-rupley

http://people.cehd.tamu.edu/ rcapraro/

http://people.cehd.tamu.edu/ mcapraro/ 